\title{
The Operational Features of Pumping Stations Equiped with Parallel- Connected Centrifugal Pumps for Land-Reclamation
}

\author{
Khalid S. Al-Rababa \\ Department of Mechanical Engineering, Tafila Applied University College \\ Al-Balqa' Applied University, P.O. Box 179, Tafila 66110, Jordan
}

\begin{abstract}
The required water supply of a pump could be provided by means of different combinations of pressure piping and pumping units at different operational costs. The basic indices describing the operational modes for the individual and group pumping units, including the values of the efficiency, are computed. The adequacy of the calculational results that based on the developed mathematical models is confirmed by the full-scale experimental researches. Based on the presented principles of the load distribution between parallel working pumping units, $5 \%$ of consumed electric power may be saved.
\end{abstract}

Key words: Land-Reclamation, Pumping Unit, Pressure Head, Model Adequacy, Water Discharge

\section{INTRODUCTION}

In this study the features of the land-reclamation pumping stations, which deliver water into the irrigating systems have been considered. The study of their operation mode should take in consideration:

* The seasonal variation

* The temporary decrease of the water supply

* The total stoppage for a short period of time under the emergency conditions

At such pumping plants, some aggregates operate on one common pressure head pipe lines (PHPL). There is a locking set at each pump of a particular pipe line. The locking set for the small pumping plants is a sliding valve, while disk shutters are applied to the large stations. Such pump stations in Uzbekistan include Khamza, Kiziltepa ,Talimardzhan (HC-7 KMK), Tashkelik, pump stations of Dzhizak and Amu-Zang cascades.

The land-reclamation pumping plants, equipped with long PHPL and several centrifugal pumps are commonly connected in prallel to one PHPL. Their operational modes basically depend on the quantity of pumping units, thier connection schemes and on the water levels in the downstream and upstream of station [1]. At the selection of a pump or group of the pumps, included in the parellel operation, it is necessary to take into account the value and the nature of a change in water folwrate, the duration of the plant operation with one or another folwrate, which in turns minimize the number of switching on and off of the pumping units. The number of startings of the large pumping units with a power of more than $2500 \mathrm{~kW}$ is limited to $50-120$ times/year [2].
Operation of Pumping Units: For the economical operation of pumping units, it is recommended to run most of time those units that have higher efficiency. Increasing the operational time for the pumps of higher efficiency and low specific consumption of electrical power from 4500 to $6240 \mathrm{hr} / \mathrm{year}$ and decreasing the operational time of the pumping unit with low efficiency and higher consumption of electrical power from 4500 to 2700 hr/year have allowed to reduce the annual power consumption of pump station to 264000 $\mathrm{kWh}$ [2].

Discharge control of the land-reclamation pumping plants, equipped with centrifugal pumps operating in parallel on a common pipe line, is accomplished step by step, via starting or turning off of pumping unit. For the organization of the operational mode for different types of pumping units, a time selection criterion is needed for the transition from one pumping unit to another. To achieve that, it is expedient to build for each pumping unit (or group of units) the curves of the specific consumption of electric power for the pumping of $1 \mathrm{~m}^{3}$ of water. The points of intersections of these curves determine the discharge quantity at which a certain unit is to be run while the other is disconnected $[2,3]$.

The Criterion for the Load Distribution: The criterion of the correct load distribution between the pumps is the minimum power consumption of the simultaneously operating pumping units. For the majority of the national pumps, the graphs of characteristic $N=f(Q)$ have the form of curves' concave downward, the minimum power consumption is ensured, if power increment for each of the parallel pumping units is equal [2 ]. 
$\frac{\mathrm{dN}_{1}}{\mathrm{dQ}}=\frac{\mathrm{dN}_{2}}{\mathrm{dQ}}=\frac{\mathrm{dN}_{3}}{\mathrm{dQ}}=\cdots=\frac{\mathrm{dN}_{\mathrm{n}}}{\mathrm{dQ}}$

The presented principles of load distribution between the parallel pumping units ensure 5\% saving of electrical power. Optimum load distribution between the pumping units, gives the equality efficiencies or specific consumption of the electric power of these units. the rotational speed of these pumps is determined from the condition of the economic operation of pumping units,

The station output is given by:

$\mathrm{I}=\mathrm{Q}_{\mathrm{c}}^{-1} \sum_{\mathrm{i}=1}^{\mathrm{n}} \mathrm{q}_{\mathrm{i}} \mathrm{H}\left(\mathrm{q}_{\mathrm{i}} \varphi_{\mathrm{i}}\right) \cdot \eta_{\mathrm{i}}^{-1}\left(\mathrm{q}_{\mathrm{i}}, \mathrm{H}_{\mathrm{i}}\right) \cdot \eta_{3 \mathrm{i}}^{-1}$,

Where:

$\mathrm{H}_{\mathrm{i}}\left(\mathrm{q}_{\mathrm{i}}, \boldsymbol{\varphi}_{\mathrm{i}}\right)$-the characteristic head of pump

$\eta_{\mathrm{i}}\left(\mathrm{q}_{\mathrm{i}}, \mathrm{H}_{\mathrm{i}}\right)$-efficiency of pump

The mathematical model for the static behavior of pumping plant take the following form [4]:

$$
\begin{aligned}
& \mathrm{Q}_{\mathrm{c}}=\sum_{\mathrm{i}=1}^{\mathrm{n}} \mathrm{q}_{\mathrm{i}}, \\
& \mathrm{N}_{\mathrm{c}}=\sum_{\mathrm{i}=1}^{\mathrm{n}} \mathrm{N}_{\mathrm{i}}, \\
& \mathrm{H}_{\mathrm{i}}=\mathrm{H}_{\Gamma}+\sum \mathrm{h}_{\mathrm{i}},
\end{aligned}
$$

Where:

$\mathrm{Q}_{\mathrm{c}}, \mathrm{N}_{\mathrm{c}}$-discharge and consumption power station

$\mathrm{H}_{\mathrm{i}}, \mathrm{H}_{\mathrm{r}}$-manometric and geometric pressures

$\Sigma$ h $\quad$ total losses in pressure head for delivery pipe line of the unit.

The Computational Algorithm: The computational algorithm of the static mode of the pumping plant with centrifugal pumps will be as follows:

1. Assignement of the group components of pumping units connected to common PHPL. For a given component, the total head characteristic is constructed. $\mathrm{H}_{\mathrm{TP}}^{\prime}=\mathrm{f}\left(\mathrm{Q}_{2}\right)$, where, $\mathrm{Q}_{2}=\Sigma \mathrm{q}_{\mathrm{i}}$.

2. The total head characteristic of pipe line is constructed, taking into account the experimental data in the zone of the actual supplies. $\mathrm{H}_{\mathrm{TP}}\left(\mathrm{Q}_{2}\right)=\mathrm{H}_{\Gamma}+\Delta \mathrm{h}_{\mathrm{TP}}\left(\mathrm{Q}_{2}\right)$.

3. The total disharge of the operating group is determined by the solution of equation:

$$
\begin{aligned}
& \left\{\mathrm{H}_{\mathrm{TP}}\left(\mathrm{Q}_{2}\right)-\mathrm{H}_{\Gamma}-\Delta \mathrm{h}_{\mathrm{TP}}\left(\mathrm{Q}_{2}\right)=0 .,\right. \\
& \left.\mathrm{H}_{\mathrm{TP}}^{\prime}=f(\mathrm{Q} \varepsilon)=\mathrm{H}_{\mathrm{TP}}\right\}
\end{aligned}
$$

4. On the basis of $\mathrm{H}_{\mathrm{TP}}$ and $\mathrm{Q} \varepsilon$ the complete pressure of each aggregate is determined.
5. From the initial head characteristic curves the supply of each unit is determined on the base of the known full head.

6. Proceeding on the calculated values of discharge and pump head, efficiency and the required power are determined by formula:

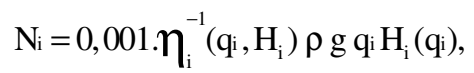

Where :

$\rho \quad$-density of flowing liquid;

g -acceleration due to gravity;

$\mathrm{N}_{\mathrm{i}} \quad$-shaft power of pump in $\mathrm{kW}$.

The task of determining the optimum distribution of the station productivity for each aggregate is reduced to the selection of such a vector of the pumping units' discharge, for which of the function of the following form is minimum:

$\mathrm{W}=\mathrm{k} \int_{\mathrm{t} 1}^{\mathrm{t} 2} \sum_{i=1}^{\mathrm{n}} \mathrm{q}_{\mathrm{i}} \mathrm{Hi}_{\mathrm{i}} \eta_{\mathrm{i}}^{-1} \mathrm{dt} \Rightarrow \min$,

This task is considered as a parametric optimization [ 3, 4 ].

Determination of $\mathbf{Q}_{\mathbf{i}}$ for all Pumping Units: From the analysis of HC-7 KMK modes it may be concluded that the closest to the given discharge of the pump station can be ensured by means of different combinations of running units and pressure piping lines, while each of them will have its own power consumption and ,consequently, the different types will have also different running costs.

Taking into account the dependency of the geometric height of pumping on the transition mode through the panel of plant water-discharge of individual head losses during the confluence of flows on pipe crosses, the steady-state regime of a group of pumping units, operating in parallel on a common delivery pipe line is described by the system of equations of the following form (for two aggregates):

$$
\begin{aligned}
& \mathrm{H}_{\mathrm{m} 1}=\mathrm{H}_{\Gamma}+\Delta \mathrm{H}_{1 \mathrm{c} . \delta}\left(\mathrm{Q}_{1}, \mathrm{Q}_{2}\right)+\Delta \mathrm{H}_{\Gamma}\left(\mathrm{Q}_{\mathrm{c}}\right) ; \\
& \mathrm{H}_{\mathrm{m} 2}=\mathrm{H}_{\Gamma}+\Delta \mathrm{H}_{\mathrm{C}, \mathrm{n}}\left(\mathrm{Q}_{1}, \mathrm{Q}_{2}\right)+\Delta \mathrm{H}_{\Gamma}\left(\mathrm{Q}_{\mathrm{C}}\right) ; \\
& \mathrm{Q}_{1}=\mathrm{QH}_{1}\left(\mathrm{H}_{\mathrm{m} 1}\right) ; \\
& \mathrm{Q}_{2}=\mathrm{QH}_{2}\left(\mathrm{H}_{\mathrm{m} 2}\right) ; \\
& \mathrm{Q}_{\mathrm{C}}=\sum_{\mathrm{i}=1}^{2} \mathrm{Q}_{\mathrm{i}},
\end{aligned}
$$

Where, $\Delta \mathrm{H}_{1 \mathrm{c} . \delta}, \Delta \mathrm{H}_{\mathrm{c} . n}$ - head Losses, determined by the composition of the working units and the corresponding modes of the confluence of the flows in the beginning of common PHPL; 
$\Delta \mathrm{H}_{\Gamma}\left(\mathbf{Q}_{\mathrm{C}}\right)$-the functional dependence of losses on the consumption of water;

$Q_{i}$ - the discharge of i-th pumping unit

$\mathrm{Q}_{\mathrm{c}}$-the total discharge of the groups of all pumping units

$\left(\mathrm{Q}\left(\mathrm{H}_{\mathrm{i}}\right)\left(\mathrm{H}_{\mathrm{mi}}\right)\right.$-the functional relationship that determines the discharge of $i$-th aggregate at pressure $\mathrm{H}_{\mathrm{mi}}$ in accordance with the performance characteristic of pump.

Solution of equations (7) determines the discharge value $\mathrm{Q}_{\mathrm{i}}$ for all of the pumping units, the total discharge of the working aggregates' group $\mathrm{Q}_{\mathrm{c}}$ and the manometric head of $\mathrm{H}_{\mathrm{mi}}$ of each aggregate, for any possible operational mode of the operating pumps and the geometric pumping head. By the caculation of the values $\mathrm{Q}_{\mathrm{i}}, \mathrm{H}_{\mathrm{mi}}, \mathrm{Q}_{\mathrm{c}}$, the basic indicators that determine the system of operation for all pumping units is:

$$
\mathrm{N}_{\mathrm{C}}=\sum_{\mathrm{i}=1}^{\mathrm{n}} \mathrm{N}_{\mathrm{i}}
$$

The mean value of efficiency for the pumping unit, operating on the same pipe line can be determined from the relation:

$$
\bar{\eta}=\frac{Q_{\mathrm{c}} \cdot H_{\mathrm{m}}}{\mathrm{N}_{\mathrm{C}}} .
$$

\section{CONCLUSION}

In this study a procedure for the caculation of the pumping plant operation equipped with centrifugal pumps has been developed with the consideration of head lossess during the confluence of flows into the common delivery pipe lines.

The comparison between the caculational and experimental results confirms the adequacy of the developed mathematical models and procedure.

\section{REFERENCES}

1. Stepanov, A.I., 1960. Centrifugal and Axial Pumps. M- Mashgiz. pp: 461.

2. Leznov, B.C., 1991. The economy of the Electrical Energy in Pumping Stations. Energy Atomzdat. pp: 144.

3. Glavatski, O.Y., B.S., Jamalov and P.A. Achilov, 1981. Improvement of Reliability in large vertical pumps. Hydraulics and melioration. pp: 9.

4. Rakhimov, S.K., A.E. Parmanov and S.C. Khzjaev, 1993. The mathematical modeling of the operational mode of large pumping stations with centrifugal pumps. HPP Water pumping/1, Tashkent, pp: 8-13. 